\title{
ANALISIS KAPASITAS STRUKTUR DINDING SQUAT WALL (STUDI KASUS UNDERPASS POMPA SENTIONG JAKARTA)
}

\author{
Anthony Costa ${ }^{1 *}$, Bimo Brata Adhitya ${ }^{1)}$, dan Kencana Verawati ${ }^{2)}$ \\ 1) Jurusan Teknik Sipil FT UNSRI, Jl. Raya Prabumulih - Km 32 Indralaya, Ogan Ilir, Sumsel \\ 2) Jurusan Teknik Sipil, FT UNJ, Jl. Rawamangun Muka, Pulogadung, Jakarta Timur, DKI Jakarta
}

\begin{abstract}
There is a potential overflow of a river during rain, resulting in water levels raised beyond normal water levels in the Sentiong Underpass Area, Jakarta in which is one of the strategic locations in Central Jakarta. To guarantee and maximize water flow in the Sentiong Underpass area, a water discharge regulatory system was created to be the form of underground wall structures equipped with pump houses. This wall structure is made of reinforced concrete structures underground at $\pm 3 \mathrm{~m}$ depth. This research aims to evaluate and analyze the underground wall capacity with reference to principles designed by SNI 2847-2013 and SNI 1727-2013. Analysis of data used based on field data including soil test parameters and vehicle traffic. Structural analysis which used is Computer Program (STAADPro), then based on the data obtained from the results of analysis and evaluation can be determined magnitude of displacement and dimensions of the reinforcement. The wall structure in Sentiong Area, Jakarta was planned to use K-300 concrete as high as $3 \mathrm{~m}$ underground, $40 \mathrm{~cm}$ of wall thickness, bottom floor thickness $40 \mathrm{~cm}$, and upper floor thickness $20 \mathrm{~cm}$. The total length of this underground wall structure was planned $32 \mathrm{~m}$. Based on the results of the analysis, it was found that displacement and capacity structure qualified safely with design steel reinforcement diameters of D13 mm and D16 $\mathrm{mm}$.
\end{abstract}

Key Words: structure capacity, reinforced concrete, underground wall.

\section{PENDAHULUAN}

Adanya potensi meluapnya air sungai saat hujan sehingga mengakibatkan kondisi muka air naik melebihi muka air normal pada Daerah Underpass Sentiong, Jakarta yang saat ini sebagai salah satu lokasi strategis di Ibukota Jakarta Pusat. Guna menjamin dan memaksimalkan muka air banjir pada daerah Underpass Sentiong, maka dibuatlah suatu struktur dinding penampung air bawah tanah sebagai pengatur debit air yang dilengkapi dengan rumah pompa. Hal ini bertujuan sebagai tempat penampungan air sementara untuk mensiasati volume air yang berlebih pada saat terjadinya hujan.

Pembangunan struktur dinding bawah tanah ini memiliki panjang $32 \mathrm{~m}$ dengan ketinggian $3 \mathrm{~m}$ dan lebar 3,2 m. Pertimbangan terhadap kondisi lapangan yang dilalui kendaraan yang intensitasnya sangat besar per hari dan juga kondisi tanah lempung terutama pada musim hujan, maka dibutuhkan analisis pembebanan terhadap kapasitas struktur yang maksimal. Pembangunan dinding bawah tanah ini tidak terlepas dari kondisi geologi, geografis dan lingkungan sekitar. Penerapan struktur dinding beton bertulang pada lokasi ini bertujuan selain untuk menampung debit air banjir juga berguna untuk mengalihkan air pada bak penampungan bawah tanah. Berdasarkan beberapa hasil uji di lapangan, kondisi tanah di daerah Underpass Sentiong, Jakarta ini merupakan tanah lempung dengan beberapa rembesan air yang terjadi pada kedalaman $\geq 2 \mathrm{~m}$.

Menurut Fian (2016), dinding penahan tanah merupakan suatu konstruksi yang dibuat untuk menahan tanah yang mempunyai kemiringan dan menahan tekanan tanah lateral akibat kondisi topografi. Untuk menganalisis gaya lentur yang diterima oleh struktur dinding penahan maka diperlukan penulangan yang dihitung berdasarkan momen ultimate akibat gaya dan beban yang diterima salah satunya yaitu Gaya Horizontal akibat Beban Tanah (Jumaidi, 2019).

Menurut Teresa (2019), dinding struktur beton bertulang merupakan aplikasi struktur dengan material beton bertulang yang didesain terhadap gempa, dinding struktur ini digunakan untuk memperkuat dan memperkaku struktur bangunan. Dinding dengan rasio perbandingan tinggi dinding terhadap panjang dinding $\left(\mathrm{h}_{\mathrm{w}} / \mathrm{l}_{\mathrm{w}}\right)$ yang lebih kecil memiliki kekuatan yang lebih besar dibandingkan dengan dinding yang mempunyai rasio lebih besar (Teng dan Candra, 2016).

Pada umumnya perencanaan dinding geser dikategorikan berdasarkan geometri antara lain: 
a) Squat wall (dinding pendek) dengan kategori syarat dinding geser memiliki rasio perbandingan tinggi dinding $\left(\mathrm{h}_{\mathrm{w}}\right)$ terhadap panjang dinding $\left(\mathrm{l}_{\mathrm{w}}\right)$ $\leq 2$, desain dikontrol terhadap perilaku lentur

b) Flexural wall (dinding langsing), dengan kategori syarat memiliki rasio perbandingan tinggi dinding $\left(\mathrm{h}_{\mathrm{w}}\right)$ terhadap panjang dinding $\left(\mathrm{l}_{\mathrm{w}}\right)$ $\geq 2$, desain dikontrol terhadap perilaku lentur

c) Coupled Shear Wall (dinding berangkai), dengan kategori syarat momen guling yang terjadi akibat beban gempa ditahan oleh balok yang terhubung dengan dinding geser sebagai akibat beban dari gaya tarik yang bekerja pada dinding.

Menurut Fajar (2017), dalam suatu perencanaan dinding geser perlu diperhatikan bahwa dinding geser tersebut mampu dan tidak boleh runtuh akibat gaya lateral yang besar terutama beban gempa, hal ini dikarenakan jika struktur dinding tersebut runtuh maka keseluruhan elemen struktur juga akan runtuh akibat tidak mampu menahan gaya lateral.

Dengan memperhatikan beberapa hal tersebut diatas yaitu nilai rasio perbandingan tinggi dinding terhadap panjang dinding sebesar $0,093 \leq 2$ maka perlu dibangun suatu struktur dinding yang kokoh tipe Squat Wall sebagai salah satu solusi struktur bawah tanah penampung debit banjir pada daerah underpass Sentiong. Permasalahan ini dibatasi pada perencanaan desain tipe beton bertulang dengan mengacu kepada syarat aman nilai lendutan izin struktur dan analisis kapasitas penulangan. Adapun manfaat dari penelitian ini yaitu dapat mengetahui syarat aman dari konstruksi dinding bawah tanah berdasarkan hasil analisis terhadap tegangan regangan, perpindahan serta hasil perencanaan struktur berupa penulangan.

\section{METODOLOGI}

Kondisi denah dan potongan eksisting berdasarkan data pengukuran dilapangan menunjukkan bahwa posisi dinding struktur tipe squat wall ini pada area underpas kemayoran sisi timur. Adapun elevasi bottom dari struktur bangunan berada pada $-5,35$. Hal ini dapat dilihat pada Gambar 1 dan 2 berikut.

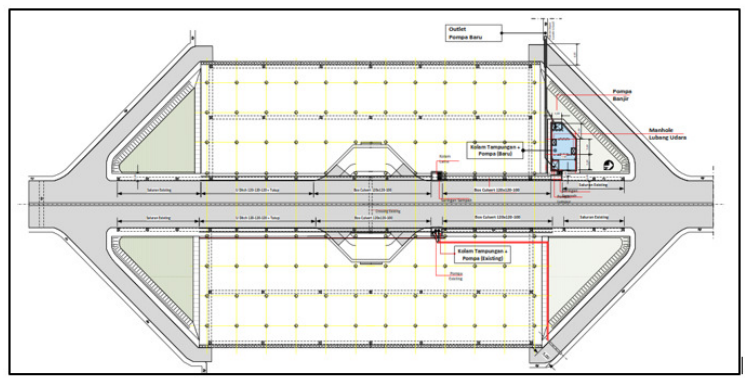

Gambar 1. Denah Lokasi Struktur Dinding

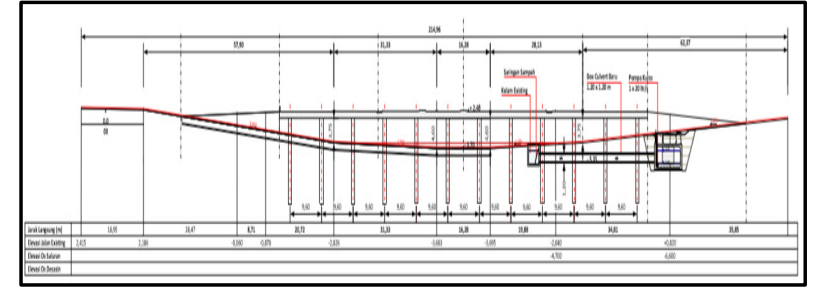

Gambar 2. Potongan Memanjang Struktur Dinding

Data yang digunakan dalam perhitungan desain struktur dinding beton bertulang ini meliputi hasil uji lab geoteknik dan pengukuran eksisting. Pengujian laboratorium geoteknik ini bertujuan untuk mengetahui sifat dan parameter tanah dilokasi dengan sketsa desain mengacu kepada Gambar 3 dan Gambar 4 yaitu nilai dari High Water Level sebesar 4,05 dan Low Water Level sebesar -6,00 dengan dimensi tinggi dinding $3 \mathrm{~m}$, panjang dinding $32 \mathrm{~m}$, tebal dinding samping $40 \mathrm{~cm}$, tebal lantai bawah semula $30 \mathrm{~cm}$ diubah menjadi $40 \mathrm{~cm}$ dan tebal lantai atas semula $30 \mathrm{~cm}$ diubah menjadi $20 \mathrm{~cm}$.

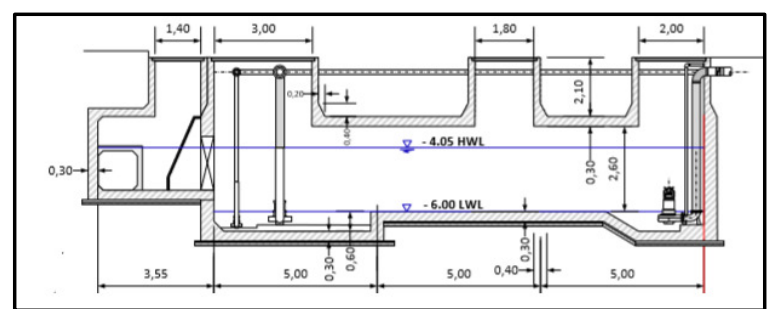

Gambar 3. Sketsa Dimensi Struktur Dinding

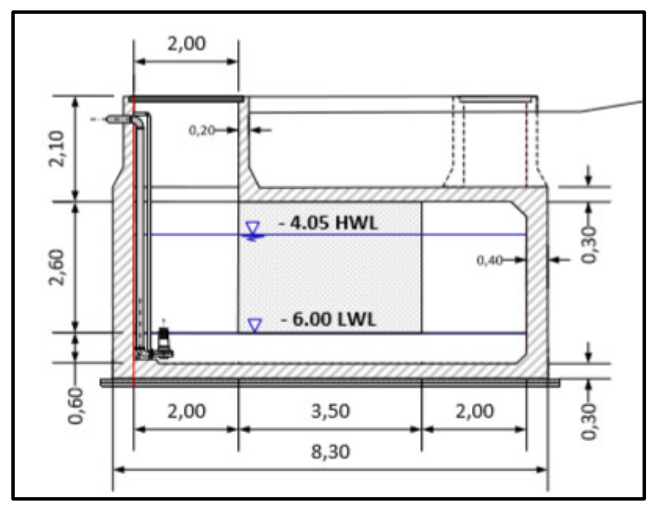

Gambar 4. Sketsa Dimensi Struktur Dinding

Setelah mendapatkan data tersebut, maka dilakukanlah metode pemodelan matematis yaitu analisis kapasitas pemodelan 3 dimensi dengan bantuan perangkat lunak berbasis elemen hingga (STAADPro) dengan cara mengecek nilai stress strain dan lendutan izin struktur sehingga kondisi desain mewakili kondisi di lapangan. Pemodelan matematis dilakukan dengan memodelkan struktur dinding berupa Elemen Pelat, pada tahapan pemodelan ini juga dilakukan meshing element sehingga bentuk pemodelan matematis mewakili dimensi struktur di lapangan. Pemodelan struktur ini dapat dilihat pada Gambar 5 dan Gambar 6 di bawah ini. 


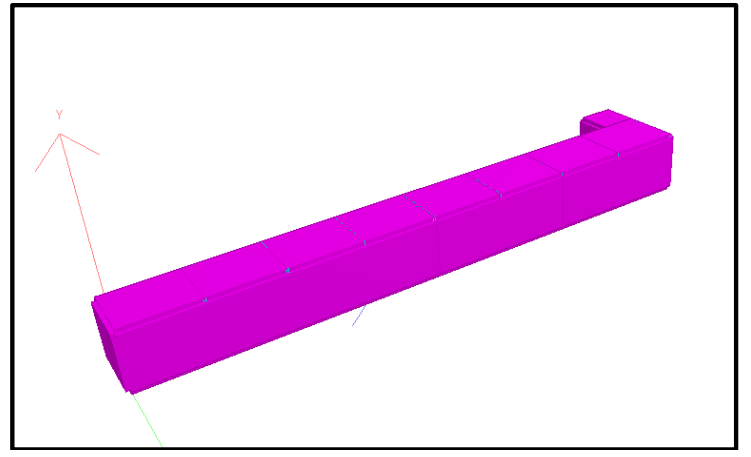

Gambar 5. Pemodelan 3D Struktur Dinding (STAADPro)

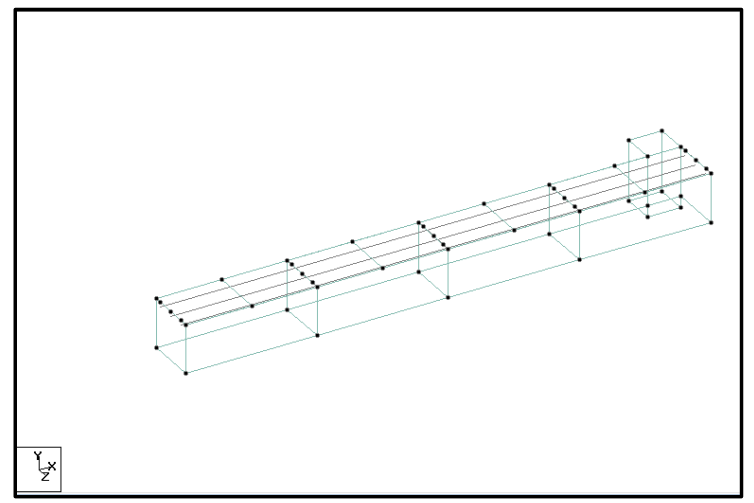

Gambar 6. Pemodelan 3D Struktur Dinding (STAADPro)

\section{Perancangan Struktur Dinding}

Perencanaan struktur dinding beton bertulang ini memiliki beberapa karakteristik bahan dan komponen konstruksi. Adapun bahan material beton yang digunakan menggunakan mutu beton fc' 25 MPa dan mutu baja tulangan fy $390 \mathrm{MPa}$ (baja ulir), beberapa parameter desain lain diantaranya tebal lantai bagian bawah yaitu $50 \mathrm{~cm}$, tebal dinding $40 \mathrm{~cm}$ dan tebal lantai atas $20 \mathrm{~cm}$. Pemodelan desain pada STAADPro menggunakan dimensi plate thickness dengan pembebanan struktur sebagai berikut :

a) Beban Mati (Dead Load), yaitu berat dari seluruh material/bahan yang menimbulkan suatu beban bersifat pasif pada struktur dinding yang berupa elemen struktural berupa berat sendiri (selfweight) ditambah beban mati tambahan sebesar $100 \mathrm{~kg}$. Hal ini dapat dilihat pada Gambar 7 berikut ini :

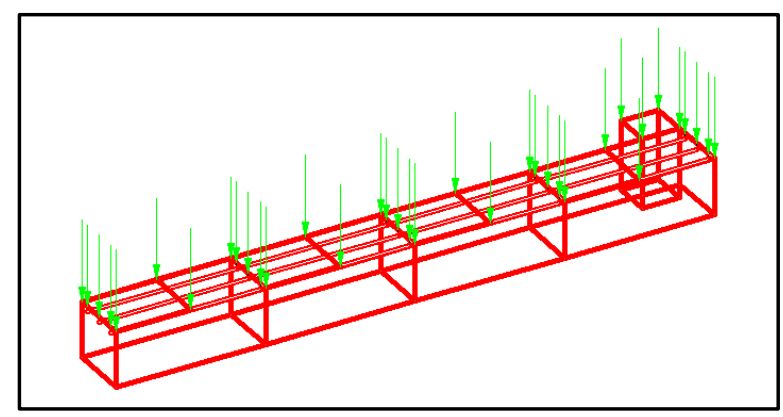

Gambar 7. Aplikasi Dead Load pada Pemodelan Struktur Dinding b) Beban Hidup (Live Load), yaitu beban bergerak yang mengacu kepada SNI 1727-2013 sebesar $150 \mathrm{~kg}$ dan dimodelkan sebagai beban terpusat dengan detail antara lain pada posisi pompa kapasitas $10 \mathrm{~m}^{3} / \mathrm{s}$ (2 pompa) sebesar $1000 \mathrm{~kg} / \mathrm{m}^{2}$ dan pada posisi pompa kapasitas $15 \mathrm{~m}^{3} / \mathrm{s}(2$ pompa) sebesar $1250 \mathrm{~kg} / \mathrm{m}^{2}$. Pemodelan beban hidup ini dapat dilihat pada Gambar 8 berikut ini.

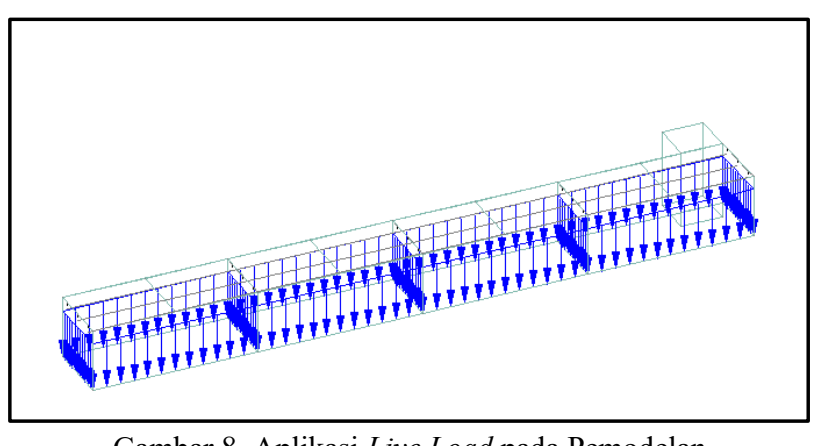

Gambar 8. Aplikasi Live Load pada Pemodelan Struktur Dinding

c) Beban Tanah (Soil Load), yaitu berupa tekanan tanah lateral jenuh air disamping atau dibelakang dinding struktur. Tekanan tanah ini dimasukkan sebagai beban segitiga yang bekerja searah horizontal tegak lurus dinding berupa tekanan tanah lempung (N-SPT 4) senilai 81,45 kN. Selain itu, diberikan juga gaya uplift (Ginting, 2016) yang diakibatkan oleh tekanan dari dasar lantai. Pemodelan beban tanah ini dapat dilihat pada Gambar 9 berikut ini.

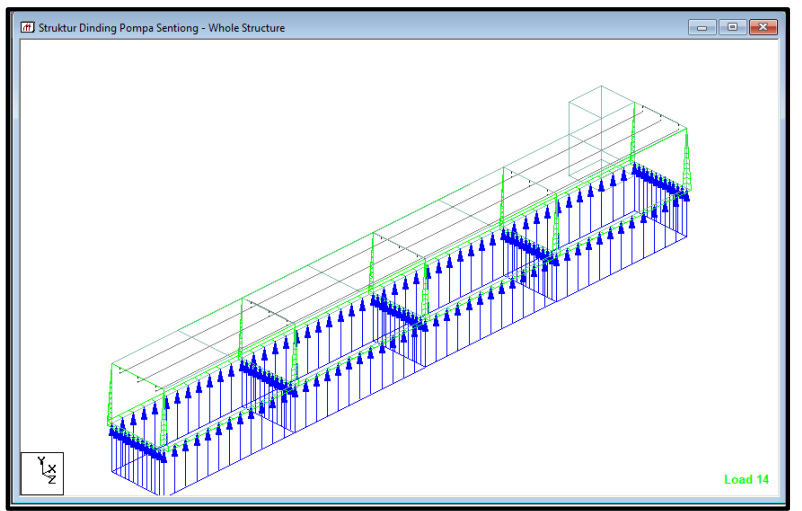

Gambar 9. Aplikasi Soil Load pada Pemodelan Struktur Dinding

d) Beban Kendaraan (Moving Load), yaitu berupa beban dari truk yang dimodelkan sebagai beban $\mathrm{T}$ dari beban roda ganda seberat $25,74 \mathrm{kN}$. Pemodelan beban kendaraan ini dapat dilihat pada Gambar 10 berikut ini. 


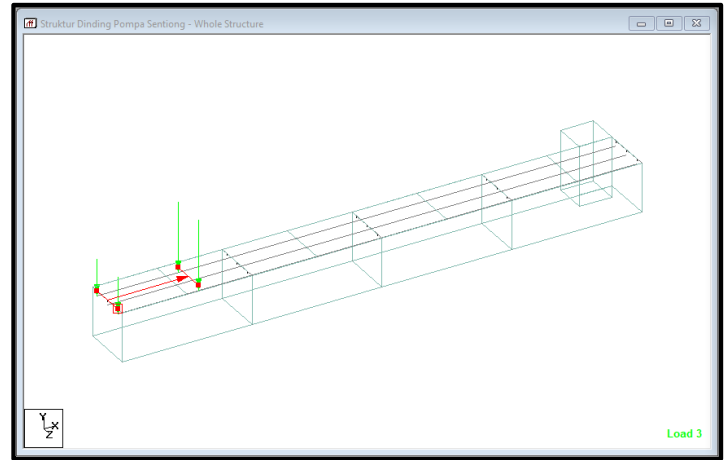

Gambar 10. Aplikasi Moving Load pada Pemodelan Struktur Dinding

\section{HASIL DAN PEMBAHASAN}

Standar desain yang digunakan dalam perencanaan Struktur Dinding Beton Bertulang ini mengacu kepada beberapa peraturan SNI yaitu :

a) SNI 03-2847-2013 tentang Tata Cara Perencanaan Beton Struktural untuk Bangunan Gedung

b) SNI 1727-2013 tentang Pembebanan Minimum untuk Bangunan Gedung dan Struktur Lain

c) SNI 1726-2012 tentang Tata Cara Perencanaan Ketahanan Gempa untuk Struktur Bangunan Gedung dan Non Gedung

d) SNI 8460-2017 tentang Persyaratan Perancangan Geoteknik

Berdasarkan kategori pembebanan dari SNI 1727 - 2013 maka pembebanan struktur dinding squat wall dapat dibagi menjadi Beban Mati (Dead Load), Beban Hidup (Live Load), Beban Kendaraan (Moving Load), Beban Air (Water Load) dan Beban Tanah (Soil Load).

Pengecekan pembebanan struktur dilakukan dengan mengaplikasikan beban kombinasi sebanyak 4 jenis antara lain yaitu :

a) Combo 1 berupa 1,4DL

b) Combo 2 berupa 1,2DL+1,6LL

c) Combo 3 berupa 1,2DL +1,6LL + 1,0WL,

d) Combo 4 berupa 1,2DL + 1,6LL +1,0SL + $1,0 \mathrm{ML}$

Beban kombinasi maksimum yang dijadikan pengecekan terhadap kapasitas struktur dinding yaitu Combo 4 berupa 1,2 DL + 1,6 LL + 1,0 WL + 1,0 SL + 1,0 ML (SNI 1727 -2013).

Berdasarkan beban kombinasi maksimum tersebut, pengecekan analisis kapasitas struktur mengacu kepada analisis antara lain :

a) Nilai stress contour yang berhubungan nilai momen ultimate pada arah sumbu X dan sumbu $\mathrm{Z}$.

b) Syarat aman dari kapasitas momen penampang struktur (Mn) yang tidak melebihi momen ultimate struktur $(\mathrm{Mu})$ yaitu $\phi * \mathrm{Mn} \geq \mathrm{Mu}(\mathrm{SNI}$ 2847 - 2013).

c) Syarat aman dari kapasitas kuat geser penampang $(\mathrm{Vn})$ yang tidak melebihi kuat geser ultimate $(\mathrm{Vu})$ yaitu $\phi * \mathrm{Vn} \geq \mathrm{Vu}$ (SNI 2847 2013).

d) Kontrol terhadap prilaku struktur menggunakan syarat terhadap nilai displacement struktur yang terjadi tidak boleh melebihi syarat displacement izin pada pelat sebesar $\mathrm{Ln} / 280$.

Setelah semua tahapan analisis strutkur tersebut dilakukan maka didapatkanlah nilai dari output proses analisis berupa kontur stress strain dan lendutan (displacement) dapat dilihat pada Gambar 10 dan 11 berikut ini.

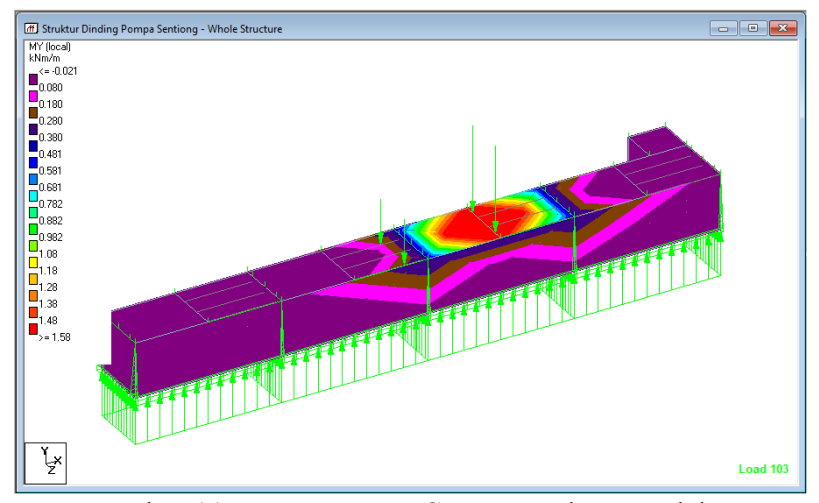

Gambar 11. Output Stress Contour pada Pemodelan

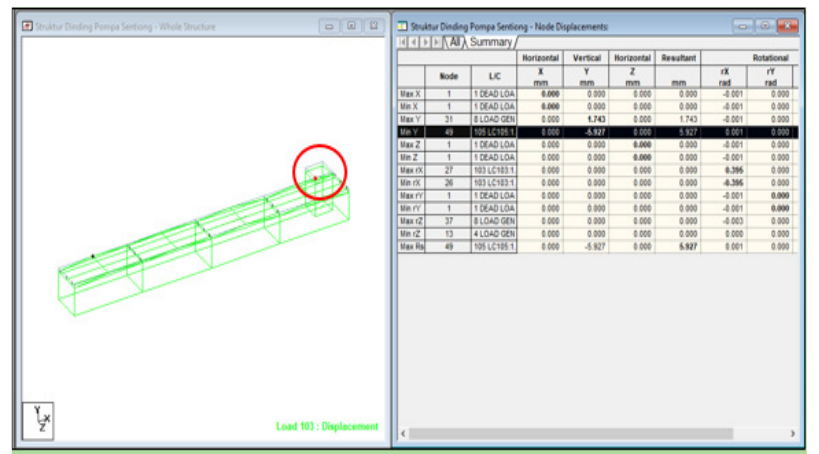

Gambar 12. Output Lendutan pada Pemodelan

Dari hasil analisis pada Gambar 11 dan 12 diatas maka dapat disimpulkan bahwa jika ditinjau berdasarkan hasil stress contour maka beban terbesar yang terjadi pada struktur dinding terjadi pada lantai atas dibagian tengah struktur. Sedangkan, jika ditinjau terhadap syarat aman dari Lendutan Izin $\left(\delta_{\text {izin }}\right)$, maka didapatkan bahwa nilai lendutan pada struktur dinding masih memenuhi syarat aman yaitu $\delta_{\text {struktur }}=0,186 \mathrm{~mm} \leq \delta_{\text {izin }}=17,285 \mathrm{~mm}$. Berdasarkan dua hal tersebut maka dapat disimpulkan bahwa Struktur Dinding Bawah Tanah memenuhi syarat aman dengan rekap hasil pemodelan Struktur Dinding dapat dilihat pada Tabel 1. 
Cantilever |Volume: 10 Nomor: 02 Oktober 2021 ISSN: 1907-4247 (Print) $\mid$ ISSN: 2477-4863 (Online) | Website: http://cantilever.id Anthony Costa, dkk. | Analisis Kapasitas Struktur Dinding Squat Wall (Studi Kasus Underpass Pompa Sentiong, Jakarta)

Tabel 1. Output Pemodelan Analisis Kapasitas pada Struktur Dinding

\begin{tabular}{lccc}
\hline \multicolumn{1}{c}{ Lokasi } & $\begin{array}{c}\mathrm{Mx} / \mathrm{My} \\
(\mathrm{kN.m})\end{array}$ & Lendutan $(\mathrm{mm})$ & $\begin{array}{c}\text { Penulangan Struktur } \\
(\mathrm{mm})\end{array}$ \\
\hline Dinding Atas & $26,9 / 158,4$ & $5,927(\mathrm{OK} !)$ & $\mathrm{D} 13-300 / \mathrm{D} 16-150$ \\
Dinding Bawah & $82,5 / 197,7$ & - & D16-275/D16-200 \\
Dinding Samping & $17,2 / 101,26$ & - & $\mathrm{D} 13-300 / \mathrm{D} 16-275$ \\
\hline
\end{tabular}

\section{KESIMPULAN}

Pada perancangan struktur dinding beton bertulang ini maka dapat disimpulkan bahwa nilai stress strain terbesar akibat pembebanan struktur terjadi pada area lantai atas dengan nilai displacement terbesar yang terjadi memenuhi syarat aman. Desain Struktur dinding dapat menggunakan beton mutu K-300 dengan pemakaian baja tulangan ulir D13 s.d D16 mm.

\section{UCAPAN TERIMA KASIH}

Penulis mengucapkan terimakasih kepada semua pihak yang ikut serta terlibat dan mendukung serta membantu dalam penulisan ini.

\section{REFERENSI}

Fian, P., Riahdrdjo H. P., Haza Z. F. (2016). Underpass Jombor Menggunakan Program Plaxis V8, 1(2)

Jumaidi., Habir H., Suratmi. (2019). Perancangan Struktur Dinding Penahan Tanah pada Pekerjaan Penanganan Longsoran Jalan Batu Cermin Samarinda, 1(1)

Teresa, F.A.., Chandra J., Purnomo, J. (2019). Kapasitas Geser Dinding Struktur Beton Bertulang dengan memperhitungkan Pengaruh Rasio terhadap Panjang Dinding, 8(1)

Teng, S., and Chandra, J. (2016). Cyclic Shear Behavior of High Strength Concrete Structural Walls. ACI Structural Journal. Vol.113, No. 6, 1335-1345

Fajar, N. (2017). Pengaruh Dinding Geser terhadap Perencanaan Kolom dan Balok Bangunan Gedung Beton Bertulang, 19(1)

Badan Standarisasi Nasional. SNI 2847-2013 Persyaratan Beton Struktural Untuk Bangunan Gedung. Jakarta: Badan Standarisasi Nasional; 2013

Badan Standarisasi Nasional. SNI 1727:2013 Pembebanan Minimum untuk Bangunan Gedung dan Struktur Lain. Jakarta: Badan Standarisasi Nasional; 2013

Badan Standarisasi Nasional. SNI 1726:2013 Tata Cara Perencanaan Ketahanan Gempa untuk Struktur Bangunan Gedung dan Nongedung. Jakarta: Badan Standarisasi Nasional; 2013

Badan Standarisasi Nasional. SNI 8460: 2017 Persyaratan Perancangan Geoteknik. Jakarta: Badan Standarisasi Nasional; 2017

Ginting, P.A.A, dan Tarigan, J. (2016). Analisa Gaya Uplift pada Reservoir. Medan. 